\title{
Erratum to: The assessment of neutrophil cd64 count as an early warning marker of joint replacement infection
}

\author{
James Perry $\cdot$ Mike R. Reed $\cdot$ Ramsay Refaie $\cdot$ \\ Andrew P. Sprowson · Kenneth S. Rankin
}

Published online: 23 August 2013

(c) Springer-Verlag Berlin Heidelberg 2013

\section{Erratum to: Arch Orthop Trauma Surg \\ DOI 10.1007/s00402-013-1816-4}

Unfortunately, several author names were omitted in the original version of the article. The missing authors and their affiliations are given below:

The correct order of authors is:

James Perry · Mike R. Reed · Ramsay Refaie ·

Andrew P. Sprowson · Kenneth S. Rankin

Ramsay Refaie

Department of Trauma and Orthopaedic Surgery, Royal Victoria Infirmary, Newcastle upon Tyne, UK

The online version of the original article can be found under doi:10.1007/s00402-013-1816-4.

J. Perry $(\bowtie)$

Newcastle Upon Tyne University, Beech House, Doctors Bank, Ashley, Shropshire TF9 4LE, UK

e-mail: Japerry7@gmail.com

M. R. Reed

Department of Trauma and Orthopaedic Surgery, Wansbeck

Hospital, Ashington, UK

R. Refaie

Department of Trauma and Orthopaedic Surgery,

Royal Victoria Infirmary, Newcastle upon Tyne, UK

\section{A. P. Sprowson}

Department of Trauma and Orthopaedic Surgery,

University Hospital of Warwickshire and Coventry,

Coventry, UK

\section{K. S. Rankin}

Department of Trauma and Orthopaedic Surgery,

Musculoskeletal Research Group, Newcastle University,

Newcastle upon Tyne, UK
Andrew P. Sprowson

Department of Trauma and Orthopaedic Surgery, University Hospital of Warwickshire and Coventry, Coventry, UK Mike R. Reed

Department of Trauma and Orthopaedic Surgery, Wansbeck Hospital, Ashington, UK

Kenneth S. Rankin

Department of Trauma and Orthopaedic Surgery, Musculoskeletal Research Group, Newcastle University, Newcastle upon Tyne, UK 